(1)

George Fox

UNIVERSITY
Digital Commons @ George Fox University

Faculty Publications - School of Physical Therapy

2018

Preseason Functional Performance Test Measures Are Associated With Injury in Female College Volleyball Players

Jason Brumitt

Alma Mattocks

Jeremy Loew

Phil Lentz

Follow this and additional works at: https://digitalcommons.georgefox.edu/pt_fac

Part of the Physical Therapy Commons 


\title{
Preseason Functional Performance Test Measures Are Associated With Injury in Female College Volleyball Players
}

\author{
Jason Brumitt, Alma Mattocks, Jeremy Loew, and Phil Lentz
}

\begin{abstract}
Context: Preseason functional performance test measures have been associated with noncontact time-loss injury in some athletic populations. However, findings have been equivocal with many studies consisting of heterogeneous populations. Objective: To determine if preseason standing long jump and/or single-leg hop test scores are associated with a noncontact time-loss injury to the lower quadrant (LQ = low back or lower-extremities) in female Division III college volleyball (VB) players. Design: Prospective cohort study. Setting: National Collegiate Athletic Association Division III female VB teams. Patients: A total of 82 female college VB players (age = 18.9 [1.0] y). Main Outcome Measures: Standing long jump and single-leg hop test measures were collected at the start of the official preseason. Athletic trainers tracked all time-loss injuries and their mechanisms. Athletes were categorized as at risk if their preseason standing long jump $<80 \%$ height, bilateral single-leg hop $<70 \%$ height, and had a SLH side-to-side asymmetry $>10 \%$. Results: The noncontact time-loss overall injury rate for the LQ region in at-risk athletes was 13.5 (95\% confidence interval [CI], 4.3-31.5) per 1000 athletic exposures. At-risk athletes were significantly more likely to experience a noncontact time-loss injury than VB players in the referent group (rate ratio $=6.2 ; 95 \% \mathrm{CI}, 1.9-17.2 ; P=.008$ ). The relative risk of sustaining a noncontact time-loss injury to the LQ was 4 times greater in the at-risk group (relative risk $=4.6$; $95 \%$ CI, 2.1-10.1; $P=.01$ ). At-risk athletes were 6 times more likely to experience a foot or ankle injury (relative risk $=6.3 ; 95 \% \mathrm{CI}$, 2.1-19.2; $P=.008)$. Conclusion: Suboptimal performance on a battery of functional performance tests is associated with a significantly greater risk of noncontact time-loss injury to the LQ in female Division III college VB players.
\end{abstract}

Keywords: division III, risk factors, standing long jump, single-leg hop

Volleyball (VB) is played by millions of competitive and recreational athletes throughout the world. ${ }^{1}$ In 2017, over 27,000 female athletes competed at the college level in the United States with the National Collegiate Athletic Association (NCAA) Division III (D III) level possessing the largest number of women's teams ( $\mathrm{n}=$ 437) and female athletes $(n=6,971) .^{2}$ Although not a contact sport, VB players are at risk for noncontact overuse and traumatic injuries. ${ }^{3-7}$ Time-loss injury rates (ie, injury rates for the entire body) have been reported for women's college VB players. Practice injury rates for female D III VB players were the highest during the preseason $(5.79$ per 1000 athletic exposures $[\mathrm{AE}=$ participation in 1 practice or 1 game]) dropping to 2.60 per 1000 AEs during the season and 1.00 per 1000 AEs in the postseason. ${ }^{4}$ Game injury rates for D III VB are highest during the season at 4.0 per 1000 AEs dropping to 2.57 per 1000 AEs in the postseason. ${ }^{4}$

A majority (more than 70\%) of all time-loss VB-related injuries occur in the lower-extremities and the trunk/back region. ${ }^{4}$ The top 3 injuries experienced during college VB games are ankle ligament sprains, internal derangement of the knee, and muscle-tendon strains of the shoulder. ${ }^{4}$ The top 3 injuries sustained during college VB practices are ankle ligament sprains, muscle-tendon strains of the upper leg, and muscle-tendon strains of the lower back. ${ }^{4}$

The competitive D III college season for VB occurs during the fall academic term (late August to November). Due to NCAA rules, D III coaches have approximately $2 \frac{1}{2}$ weeks to prepare their

Brumitt is with the School of Physical Therapy, George Fox University, Newberg, OR. Mattocks is with Athletic Training Education Program, Spalding University, Louisville, KY. Loew is with Lewis \& Clark College, Portland, OR. Lentz is with Pacific University, Forest Grove, OR. Brumitt (jbrumitt@ georgefox.edu) is corresponding author. athletes prior to the first game. ${ }^{8}$ As previously mentioned, the period of time that is associated with the highest rate of injury is during the preseason. ${ }^{4}$ This injury rate may be the result of athletes failing to adequately train during the off-season (eg, unsupervised summer months) and/or due to the training volume experienced during the preseason (eg, daily double practices). Thus, identifying at-risk athletes may help coaches and/or sports medicine professionals to intervene with an individualized injury prevention training program.

A recent trend in sport science research is to prospectively evaluate the effectiveness of functional performance tests (FPTs) to discriminate injury risk in a population of athletes. ${ }^{9-13}$ The aforementioned prospective cohort studies have included VB players as part of the total subject population. ${ }^{9-13}$ Two of the aforementioned studies evaluated the relationship between jump and hop measures and injury. ${ }^{9,13}$ Asymmetrical hop distances ${ }^{9}$ and suboptimal performance on a battery of jump and hop tests ${ }^{13}$ are associated with greater injury risk in a heterogeneous population of female D III athletes. However, a concern associated with utilizing a heterogeneous sample of athletes in these types of studies is the potential for either underestimating or overestimating injury risk. ${ }^{9}$ Thus, analysis of injury risk, based on preseason FPT measures, for a homogeneous sample of athletes is warranted.

The purpose of this study is 2-fold. The primary purpose of this prospective cohort study was to determine if the standing long jump (SLJ) test and/or the single-leg hop (SLH) for distance test are associated with noncontact time-loss lower quadrant (LQ = lowerextremities and low back region) injury in female college VB players. It was hypothesized that VB athletes with shorter jump and/or hop distances would be at an increased risk for LQ injury. The secondary purpose of this study was to report injury rates for noncontact time-loss sport-related LQ injuries. 


\section{Methods}

\section{Subjects}

A total of 82 female college VB players (aged 18.9 [1.0] y) were recruited from 6 NCAA D III teams from the Portland, OR region. An athlete was excluded from study participation if she was either (1) less than 18 years at the time of testing or (2) restricted from full sport participation by either her team physician or her team athletic trainer. The institutional review board of George Fox University (Newberg, OR) approved this study. Informed consent was collected from each athlete prior to study participation.

\section{Testing Protocol}

Volleyball athletes were tested at the start of the preseason with testing occurring on a VB court. Each athlete completed a demographic questionnaire, had their height and weight measured, performed a dynamic warm-up, and then performed the FPT battery. ${ }^{14-16}$ The following information was collected from the demographic questionnaire: age, age starting sport, and years in university/college. Next, anthropometric measures were collected for height (cloth measuring tape affixed to a wall) and weight (standard medical scale). A dynamic warm-up, consisting of active movements for the LQ region, was performed for a 5-minute period immediately prior to jump and hop testing. The active movements performed during the dynamic warm-up consisted of the following: forward walking, backward walking, heel walking, tip toe walking, forward lunging, backward lunging, and high knee marching. ${ }^{9}$

\section{Standing Long Jump}

The SLJ test (also known as the broad jump) was performed first. ${ }^{14-16}$ A cloth measuring tape was affixed to the floor by athletic tape. Athletes were instructed to stand with feet positioned shoulder width apart and behind the piece of tape. Athletes were also instructed to clasp their hands behind their back for each jump. ${ }^{14-16}$ Athletes performed 3 submaximal jumps followed by 3 maximal effort SLJ. For a test to count, the athlete had to stick the landing for 5 seconds while keeping their hands clasped behind their back. ${ }^{14-16} \mathrm{~A}$ test was repeated if the athlete failed to stick the landing for 5 seconds or if she failed to keep her hands clasped behind her back. ${ }^{14-16}$ The SLJ distance was measured from the starting line to the rearmost heel. Mean scores, normalized to height, were used for statistical analysis (normalization formula: athlete's mean SLJ score/athlete's height). The primary investigator's test-retest reliability (intraclass correlation coefficient ${ }_{3,3}$ ) for the SLJ ( $0.96 ; 95 \%$ confidence interval [CI], $0.83-0.97)$ has been previously reported. ${ }^{17}$

\section{SLH for Distance}

A total of 6 SLH tests were performed; 3 per lower-extremity (LE). A coin toss was performed to determine order of testing with each trial alternating between LEs. Athletes were instructed to stand on a single LE with her foot positioned behind the piece of tape. Athletes were required to clasp their hands behind their back for each SLH. ${ }^{14-16}$ A test was repeated if the athlete failed to stick the landing for 5 seconds or if she failed to keep her hands clasped behind her back. ${ }^{14-16}$ The distance hopped was measured from the starting line to the heel. Mean scores for each leg, normalized to height, were used for statistical analysis (normalization formula: athlete's mean SLH score/athlete's height). The primary investigator's test-retest reliability (intraclass correlation coefficient ${ }_{3,3}$ ) for the (R) SLH $(0.95 ; 95 \%$ CI, 0.89-0.98) and the (L) SLH (0.96; $95 \%$ CI, 0.89-0.98) has been previously reported. ${ }^{17}$

\section{Injury Surveillance}

Injury records were maintained, starting with the first training session after testing through the end of the season, by each university's athletic training staff. The VB team's athletic trainer diagnosed each injury and collected the following information for each injured athlete: region of the body injured and the mechanism of injury (eg, contact or noncontact). Only noncontact time-loss injuries to the low back or lower-extremities were analyzed in this study. The operational definition of an injury was any muscle, joint, or bone injury to the LQ region that occurred during practice or a game via a noncontact mechanism that required the athlete to be removed from that day's event or prevented the athlete from participating in the subsequent event. ${ }^{18,19}$ The primary investigator collected injury information on a weekly basis to ensure data collection and accurate reporting.

\section{Statistical Analysis}

A minimum of 67 subjects were required to determine statistically significant associations between FPT measures and noncontact time-loss LQ injury (a priori sample size calculation was performed, based on an alpha level of .05 , power of 0.80 , and relative risk $[R R]$ of 2.0$).{ }^{9}$

Descriptive statistics (mean [SD]) were calculated for athlete's age, the number of years in college/university, the age starting sport, anthropometric measures, and normalized preseason FPT measures. Jump and hop measures were normalized as a percentage of height.

Receiver-operator characteristic curves were calculated to determine potential cutoff scores per each FPT. Analysis of generated receiver-operator characteristic curves failed to identify cutoff scores that maximized sensitivity ( $\mathrm{Sn}$ ) and specificity (Sp); thus, previously reported cutoff scores for each functional test were utilized. ${ }^{9}, 14,15$

Comparisons between at-risk/referent groups and between injured/noninjured athletes for demographic measures and normalized preseason FPT measures were calculated by performing independent $t$ tests. "At-risk" athletes were defined as an athlete whose preseason FPT measures were as follows: SLJ $<80 \%$ of one's height, bilateral SLH $<70 \%$ of one's height, and a SLH sideto-side asymmetry $>10 \%$. "Injured" athletes were defined as an athlete who sustained a noncontact time-loss injury to the LQ region during team practices or games.

Relative risk (RR) and 95\% CI were calculated per individual tests and per a combination of tests (eg, a battery of tests). Incidence rates were calculated for the total population $(\mathrm{N}=82)$ and per at-risk and referent groups. Rate ratios were calculated comparing injury rates between at-risk and referent groups. (Note: RR and rate ratios report different ratios. RR reports the difference in injury risk between the 2 groups. The rate ratio compares the rate of injury between the 2 groups.) Rates for initial and subsequent noncontact time-loss LQ injuries were calculated per 1000 AEs. Data analysis was performed using SPSS Statistics 24 (IBM, Chicago, IL) and OpenEpi (for RR, incidence rates, and rate ratios) with the alpha level set at .05 .

\section{Results}

Table 1 presents demographic information and normalized FPT measures for the entire population with comparisons between injured and noninjured athletes and between VB players in the 
Table 1 Demographic Information and Normalized FPT Measures for Female NCAA Division III VB Athletes

\begin{tabular}{|c|c|c|c|c|c|c|c|}
\hline Variable & $\begin{array}{l}\text { All VB } \\
\text { athletes } \\
(\mathrm{N}=\mathbf{8 2})\end{array}$ & $\begin{array}{c}\text { VB athletes not } \\
\text { injured during } \\
\text { the season }(n=67)\end{array}$ & $\begin{array}{c}\text { VB athletes } \\
\text { injured during } \\
\text { the season }(n=15)\end{array}$ & $\begin{array}{c}P \\
\text { value }^{*}\end{array}$ & $\begin{array}{l}\text { VB athletes } \\
\text { referent } \\
\text { group }(n=76)\end{array}$ & $\begin{array}{l}\text { VB athletes } \\
\text { at-risk group } \\
(n=6)\end{array}$ & $P$ value ${ }^{\star \star}$ \\
\hline Age, $y$ & $18.9(0.9)$ & $18.8(0.9)$ & $19.0(0.9)$ & .5 & $18.9(0.9)$ & $19.0(0.9)$ & .7 \\
\hline Years in college/university & $1.9(1.0)$ & $1.8(1.0)$ & $2.1(1.0)$ & .4 & $1.8(1.0)$ & $2.2(1.2)$ & .3 \\
\hline Age starting sport, $y$ & $11.9(2.2)$ & $12.0(2.0)$ & $11.6(3.0)$ & 6 & $11.9(2.0)$ & $12.3(3.8)$ & .5 \\
\hline Height, m & $1.71(0.08)$ & $1.70(0.08)$ & $1.72(0.06)$ & .5 & $1.70(0.08)$ & $1.75(0.06)$ & .1 \\
\hline Weight, kg & $65.9(7.6)$ & $65.7(7.5)$ & $66.9(8.0)$ & 6 & $65.7(7.4)$ & $69.7(8.6)$ & .2 \\
\hline BMI, $\mathrm{kg} / \mathrm{m}^{2}$ & $22.7(2.7)$ & $22.7(2.7)$ & $22.6(2.8)$ & .9 & $22.7(2.7)$ & $22.6(2.5)$ & .9 \\
\hline \multicolumn{8}{|l|}{ FPT measures, \%ht } \\
\hline Standing long jump & $0.82(0.10)$ & $0.82(0.09)$ & $0.82(0.10)$ & .9 & $0.82(0.09)$ & $0.72(0.06)$ & .01 \\
\hline (R) Single-leg hop & $0.67(0.11)$ & $0.67(0.11)$ & $0.67(0.11)$ & .9 & $0.68(0.10)$ & $0.54(0.12)$ & .001 \\
\hline (L) Single-leg hop & $0.66(0.11)$ & $0.66(0.11)$ & $0.65(0.11)$ & .7 & $0.67(0.10)$ & $0.49(0.15)$ & $<.001$ \\
\hline
\end{tabular}

Abbreviations: BMI, body mass index; FPT, functional performance test; ht, height; VB, volleyball. Note: Values are represented as mean (SD).

Note: *Independent $t$ tests; comparison between injured and noninjured VB athletes. ${ }^{* *}$ Independent $t$ tests; comparison between at-risk and referent groups.

Table 2 Noncontact LQ Injury Rates in Female NCAA Division III Volleyball Players, At-Risk Group Versus Referent Group

\begin{tabular}{|c|c|c|c|c|c|c|c|c|c|c|}
\hline \multirow[b]{2}{*}{ Category } & \multicolumn{3}{|c|}{ Total } & \multicolumn{3}{|c|}{ Referent group } & \multicolumn{3}{|c|}{ At-risk group } & \multirow[b]{2}{*}{ Rate ratio $(95 \% \mathrm{Cl}$} \\
\hline & $\mathbf{N}$ & AEs & Rate & $\mathbf{N}$ & AEs & Rate & $\mathbf{N}$ & AEs & Rate & \\
\hline \multicolumn{11}{|l|}{ Onset } \\
\hline Initial & 15 & 5509 & $2.7(1.6,4.4)$ & 11 & 5204 & $2.1(1.1,3.7)$ & 4 & 305 & $13.1(3.5,33.6)$ & $6.2(1.7-18.9)^{*}$ \\
\hline Subsequent & 2 & 375 & $5.3(0.9,17.6)$ & 1 & 309 & $3.2(0.0,18)$ & 1 & 66 & $15.1(0.2,84.2)$ & $4.7(0.1-182.6)$ \\
\hline Total & 17 & 5884 & $2.9(1.7,4.5)$ & 12 & 5513 & $2.1(1.1,3.8)$ & 5 & 371 & $13.5(4.3,31.5)$ & $6.2(1.9-17.2)^{* *}$ \\
\hline
\end{tabular}

Abbreviations: AEs, athletic exposures; CI, confidence interval; LQ, lower quadrant; N, number of injuries; SLJ, standing long jump; SLH, single-leg hop. Note: At-risk group: SLJ $<80 \%$ height, (B) SLH $<70 \%$ height, and SLH side-to-side asymmetry $>10 \%$.

Note: $* P=.01 . * * P=.003$.

at-risk and referent groups. There were no significant differences in demographic or FPT measures between athletes based on injury status during the season. There were significant differences in FPT measures between athletes categorized into the at-risk and referent groups. Athletes in the at-risk group had significantly shorter SLJ $(P=.005)$, (R) SLH $(P=.001)$, and (L) SLH $(P \leq .001)$ when compared with those in the referent group.

A total of 17 (15 initial and 2 subsequent) noncontact time-loss LQ injuries occurred during the study. Of the 15 initial injuries, 7 occurred in the thigh/knee region, 2 occurred at the leg, and 6 occurred in the foot/ankle region. The time-loss injuries to the thigh/knee region consisted of 2 hamstring strains, 2 anterior cruciate ligament sprains, 1 patella subluxation, and 2 knee sprains (not otherwise specified). The diagnoses for the 2 leg injuries were medial tibial stress syndrome and a leg strain (not otherwise specified). The diagnoses for the 6 injuries in the foot and ankle region were 3 lateral ankle sprains and 3 foot sprains. The 2 subsequent injuries were medial tibial stress syndrome and a fibular fracture.

The overall noncontact time-loss LQ injury rate for the total population was 2.9/1000 AEs (95\% CI, 1.7-4.5; Table 2). Athletes in the at-risk group were 6 times more likely to experience a noncontact time-loss LQ injury than their counterparts in the referent group (rate ratio $=6.2 ; 95 \% \mathrm{CI}, 1.9-17.2 ; P<.003$ ). Atrisk athletes were also 6 times more likely to experience an initial injury (rate ratio $=6.2 ; 95 \% \mathrm{CI}, 1.7-18.9 ; P<.01$ ). There was no difference in subsequent injury rates between groups.
Table 3 presents the RR associated with injury based on individual FPT scores, asymmetry between lower-extremities during the SLH and multiple FPT measures. Individual measures (eg, shorter SLJ and SLH scores or a larger SLH side-to-side asymmetry $[>10 \%]$ ) were not associated with a greater risk of injury. Combining measures into a battery of tests did reveal significant associations between injury and suboptimal scores. An at-risk athlete (eg, suboptimal SLJ and bilateral SLH measures combined with an SLH side-to-side asymmetry $>10 \%$ ) was 4 times more likely $(\mathrm{RR}=4.6 ; 95 \% \mathrm{CI}, 2.1-10.1 ; P=.01)$ of having a noncontact time-loss LQ injury. The Sn and $\mathrm{Sp}$ associated with this risk profile were 26.7 (95\% CI, 7.8-55.1) and 97.0 (95\% CI, 89.6-99.6), respectively. At-risk VB players were 6 times more likely $(\mathrm{RR}=6.3 ; 95 \% \mathrm{CI}, 2.1-19.2 ; P=.01)$ to experience a noncontact time-loss injury to the foot and ankle region. The $\mathrm{Sn}$ associated with suboptimal FPT scores and foot and ankle injuries was 33.3 (95\% CI, 7.5-70.0) and the $\mathrm{Sp}$ was 95.9 (95\% CI, 88.4-99.1). No significant relationships were observed if the athlete had suboptimal SLJ and SLH measures without a SLH side-to-side asymmetry.

\section{Discussion}

Individual FPT measures (eg, SLJ test only or SLH test only) are not associated with a greater risk of injury in D III female VB players; however, suboptimal performance on a battery of FPT is 
Table 3 Relative Risk for Noncontact Time-Loss LQ Injury Based on Preseason Functional Performance Test Measures for Female NCAA Division III Volleyball Players

\begin{tabular}{|c|c|c|c|c|c|c|c|}
\hline Categories & $\begin{array}{c}\text { Subjects } \\
\text { per category }\end{array}$ & $\begin{array}{c}\text { All injuries, } \\
\% \\
\end{array}$ & $\begin{array}{c}\text { RR (95\% Cl) } \\
\text { all LQ injuries }\end{array}$ & $\begin{array}{l}\text { Thigh/knee } \\
\text { injuries, \% }\end{array}$ & $\begin{array}{c}\mathrm{RR}(95 \% \mathrm{Cl}) \\
\text { thigh/knee injuries }\end{array}$ & $\begin{array}{l}\text { Ankle/foot } \\
\text { injuries, \% }\end{array}$ & $\begin{array}{c}\mathrm{RR}(95 \% \mathrm{Cl}) \\
\text { ankle/foot injuries }\end{array}$ \\
\hline \multicolumn{8}{|l|}{ SLJ } \\
\hline $80 \%$ or more & 42 & 17 & 1.0 (referent) & 10 & 1.0 (referent) & 7 & 1.0 (referent) \\
\hline $79 \%$ or less & 40 & 20 & $1.2(0.5-3.0)$ & 5 & $0.5(0.1-2.7)$ & 15 & $2.1(0.6-7.8)$ \\
\hline \multicolumn{8}{|l|}{ (R) $\mathrm{SLH}$} \\
\hline $70 \%$ or more & 31 & 13 & 1.0 (referent) & 6 & 1.0 (Referent) & 6 & 1.0 (referent) \\
\hline $69 \%$ or less & 51 & 22 & $1.7(0.6-4.8)$ & 8 & $1.2(0.2-6.3)$ & 14 & $2.1(0.5-10.0)$ \\
\hline \multicolumn{8}{|l|}{ (L) SLH } \\
\hline $70 \%$ or more & 28 & 18 & 1.0 (referent) & 11 & 1.0 (referent) & 8 & 1.0 (referent) \\
\hline $69 \%$ or less & 54 & 19 & $1.0(0.4-2.7)$ & 6 & $0.5(0.1-2.4)$ & 13 & $1.8(0.4-8.2)$ \\
\hline \multicolumn{8}{|c|}{ SLH side-to-side asymmetry } \\
\hline $\begin{array}{l}>10 \% \\
\text { difference }\end{array}$ & 20 & 30 & $2.1(0.8-5.1)$ & 10 & $1.6(0.3-7.8)$ & 20 & $2.5(0.7-8.4)$ \\
\hline $\begin{array}{l}10 \% \text { difference } \\
\text { or less }\end{array}$ & 62 & 15 & 1.0 (referent) & 6 & 1.0 (referent) & 8 & 1.0 (referent) \\
\hline \multicolumn{8}{|c|}{ Combined categories } \\
\hline $\begin{array}{l}\text { SLJ }<80 \% \text { and } \\
\text { (B) } \text { SLH }<70 \%\end{array}$ & 31 & 26 & $1.9(0.8-4.7)$ & 6 & $0.8(0.2-4.2)$ & 19 & $3.3(0.9-12.2)$ \\
\hline Referent & 51 & 14 & 1.0 (referent) & 8 & 1.0 (referent) & 6 & 1.0 (referent) \\
\hline $\begin{array}{l}\text { SLJ }<80 \% \text { and } \\
\text { (B) SLH }<70 \% \text {, } \\
\text { and SLH } \\
\text { side-to-side } \\
\text { asymmetry } \\
>10 \%\end{array}$ & 6 & 67 & $4.6(2.1-10.1)^{*}$ & 17 & $2.2(0.3-16.1)$ & 50 & $6.3(2.1-19.2)^{* *}$ \\
\hline Referent & 76 & 15 & 1.0 (referent) & 7 & 1.0 (referent) & 8 & 1.0 (referent) \\
\hline
\end{tabular}

Abbreviations: CI, confidence interval; LQ, lower quadrant; RR, relative risk; SLH, single-leg hop; SLJ, standing long jump.

Note: $* P=.01$. $* * P=.01$.

associated with an increased risk of injury to the LQ region. These inexpensive and quick-to-administer tests could be included as part of a preseason screening program to identify athletes who may be at risk for a noncontact time-loss LQ injury during the season.

There are several important findings associated with this study. First, female D III college VB players who present at the start of the season with suboptimal scores on a battery of tests (eg, SLJ $<80 \%$ height, bilateral SLH $<70 \%$ height, and SLH side-to-side asymmetry $>10 \%$ ) had a greater risk of a noncontact time-loss LQ injury than those in the referent group. The FPTs used in this study, the SLJ and the SLH, are frequently used as clinical correlates for LE strength. ${ }^{20-24}$ As previously mentioned, these quick-to-perform tests do not require expensive equipment, thus potentially making them ideal tests that can be administered by a certified athletic trainer, a sports medicine staff member, or other members of the coaching team. Second, the findings from this study highlight the potential benefit associated with administering a battery of tests to screen athletes for injury risk. There was no difference in individual FPT measures between those who were injured during the season and their uninjured counterparts. In addition, performance on an individual test was not associated with an increased risk of LQ injury. Once the at-risk profile was established, based on suboptimal performance on all of the tests, significant differences in preseason FPT measures were observed between groups (at risk/ referent) and those in the at-risk group were at a greater risk for LQ sports injury. Finally, this study presents novel injury rates for a population of female D III VB athletes. These rates highlight the relevance of identifying at-risk athletes. Previously reported rates of time-loss injury in female college VB players was $4.01(95 \% \mathrm{CI}$, 3.70-4.31) per 1000 AE during games and 3.70 (95\% CI, 3.503.89) per $1000 \mathrm{AE}$ during practices; however, these rates included all injury mechanisms (eg, contact and noncontact) and all locations of the body. ${ }^{4}$ The incidence rates presented in this study are novel because they (1) are restricted to the LQ region, (2) include only noncontact-related injuries, and (3) allow for comparison between athletes based on preseason FPT performance. The overall noncontact time-loss LQ injury rate in this study was 2.9 (95\% CI, 1.7-4.5) per $1000 \mathrm{AE}$; however, the overall LQ injury rate in at-risk athletes was 13.5 (95\% CI, 4.3-31.5) per 1000 AE. At-risk athletes were significantly more likely to sustain a time-loss injury than those in the referent group. Appreciating this difference highlights the importance of identifying at-risk athletes and intervening with injury prevention strategies. ${ }^{25}$

There are several strengths associated with this study. First, this study utilized a prospective cohort design. A prospective cohort design reduces the risk of bias that can occur when utilizing other epidemiologic study designs. ${ }^{26}$ Second, this study utilized tests that can be administered and interpreted quickly by sports medicine professionals and/or coaches. These tests could be administered to the athletes during the spring academic term prior to the athletes leaving campus for the summer break. Athletes with suboptimal jump and hop measures could be prescribed a targeted 
off-season training program to increase their LE strength and power. Third, the subject population consisted of a homogeneous population of female D III athletes. To our knowledge, this is the first prospective cohort study to assess injury risk based on preseason FPT measures in a population of female D III college VB players. Prior studies $^{9-13}$ that have assessed injury risk in relation to preseason FPT measure(s) have included VB players as part of a heterogeneous population. Two of the aforementioned studies evaluated the effectiveness of the SLJ and SLH to discriminate injury risk in D III athletes. ${ }^{9,13}$ The SLJ and SLH tests, as individual measures, were not associated with a greater risk of injury in a heterogeneous population of female D III athletes. ${ }^{9}$ However, female D III college athletes who had a SLJ $>80 \%$ height, bilateral SLH $>65 \%$ height, and a time $>118$ seconds on the LE functional test were 9 times more likely (odds ratio $=9.7 ; 95 \% \mathrm{CI}, 2.3-39.9 ; P=.002$ ) to sustain a time-loss LQ injury. ${ }^{13}$ This study highlights the importance of developing a risk profile based on several measures associated with athletic performance (eg, strength, speed, agility, etc.).

There are a few limitations associated with this study. First, this study only consisted of female D III college VB players; thus, the risk profile may not be generalizable to other levels of competition. Second, although at-risk athletes had a significantly greater risk of injury than athletes in the referent group, this risk profile failed to account for all potential noncontact time-loss-related injuries. There were a total of 15 initial time-loss-related LQ injuries that occurred during the course of this study with 11 injuries experienced in the referent group (11 of 76 subjects; 14\%) and 4 in the at-risk group (4 of 6 subjects; 67\%). The $\mathrm{Sn}$ associated with the risk profile in this study was low (26.7\%), whereas the Sp was high (97.0\%). On the one hand, a high $\mathrm{Sp}$ score is relevant and clinically useful. When a test (eg, the risk profile in this study) has a high $\mathrm{Sp}$, one can apply the SpPin mnemonic. ${ }^{27}$ If an athlete has a positive test (eg, suboptimal scores on all FPT) and that test battery has high specificity, it helps to rule in the potential condition (or in this case, the potential for injury) ${ }^{27}$ However, this testing battery had a low $\mathrm{Sn}$ limiting the ability to rule out the risk for injury in the presence of a negative test (eg, SnOut). ${ }^{27}$ To address the aforementioned limitations, future investigations should assess prospectively additional potential risk factors, in addition to the SLJ and SLH, in both specific (eg, one level of competition) and heterogeneous (eg, all levels of college competition) VB populations.

\section{Conclusion}

A battery of FPT, consisting of the SLJ and the SLH test for distance, may be used to screen female D III college VB athletes at risk for a sports-related LQ injury. These tests are inexpensive and quick-to-administer. These tests could be performed during the spring prior to athletes leaving campus for the summer break. Athletes with suboptimal FPT scores could be prescribed an individualized exercise program to address LE strength deficits.

\section{References}

1. Northern California Volleyball Association. History of volleyball. 2017. http://ncva.com/info/general-info/history-of-volleyball/. Accessed December 20, 2017

2. Scholarship Stats.com. College volleyball and scholarship opportunities. 2017. http://scholarshipstats.com/volleyball.htm. Accessed December 20, 2017.
3. Eerkes K. Volleyball injuries. Curr Sports Med Rep. 2012;11(5): 251-256. PubMed ID: 22965348 doi:10.1249/JSR.0b013e 3182699037

4. Agel J, Palmieri-Smith RM, Dick R, Wojtys EM, Marshall SW. Volleyball injuries: National Collegiate Athletic Association Injury Surveillance System, 1988-1989 through 2003-2004. J Athl Train. 2007;42(2):295-302. PubMed ID: 17710179

5. Agel J, Rockwood T, Klossner D. Collegiate ACL injury rates across 15 sports: National Collegiate Athletic Association Injury Surveillance System data update (2004-2005 through 2012-2013). Clin J Sport Med. 2016;26(6):518-523. PubMed ID: 27315457 doi:10. 1097/JSM.0000000000000290

6. Reeser JC, Gregory A, Berg RL, Comstock RD. A comparison of women's collegiate and girls' high school volleyball injury data collected prospectively over a 4-year period. Sports Health. 2015;7(6):504-510. PubMed ID: 26502443 doi:10.1177/ 1941738115600143

7. Powell JW, Dompier TP. Analysis of injury rates and treatment patterns for time-loss and non-time-loss injuries among collegiate student-athletes. J Athl Train. 2004;39(1):56-70. PubMed ID: 15085213

8. National Collegiate Athletic Association. NCAA 2016-2017 Division III manual. 2016. http://www.ncaapublications.com/productdownloads/ D317.pdf. Accessed December 14, 2017.

9. Brumitt J, Heiderscheit BC, Manske RC, Niemuth PE, Rauh MJ. Lower extremity functional tests and risk of injury in division III collegiate athletes. Int J Sports Phys Ther. 2013;8(3):216-227. PubMed ID: 23772338

10. Brumitt J, Heiderscheit BC, Manske RC, Niemuth PE, Mattocks A, Rauh MJ. The lower-extremity functional test and lower-quadrant injury in NCAA Division III athletes: a descriptive and epidemiologic report. J Sport Rehabil. 2016;25(3):219-226. PubMed ID: 25946403 doi:10.1123/jsr.2014-0316

11. Mokha M, Sprague PA, Gatens DR. Predicting musculoskeletal injury in National Collegiate Athletic Association Division II athletes from asymmetries and individual-test versus composite functional movement screen scores. J Athl Train. 2016;51(4):276-282. PubMed ID: 26794630 doi:10.4085/1062-6050-51.2.07

12. Smith CA, Chimera NJ, Warren M. Association of y balance test reach asymmetry and injury in division I athletes. Med Sci Sports Exerc. 2015;47(1):136-141. PubMed ID: 24870573 doi:10.1249/ MSS.0000000000000380

13. Brumitt J, Heiderscheit B, Manske R, Niemuth PE, Mattocks A, Rauh MJ. Preseason functional test scores are associated with future sports injury in female collegiate athletes. J Strength Cond Res. 2018;32(6):1692-1701. PubMed ID: 28930873 doi:10.1519/JSC. 0000000000002243

14. Davies GJ, Zillmer DA. Functional progression of a patient through a rehabilitation program. Orthop Phys Ther Clin N Am. 2009;9(2): 103-117.

15. Davies GJ, Heiderscheit BC, Clark M. The scientific and clinical rationale for the use of open and closed kinetic chain rehabilitation. In: Ellenbecker TS, ed. Knee Ligament Rehabilitation. Philadelphia, PA: Churchill Livingstone; 2000:291-300.

16. Reiman MP, Manske RC. Functional Testing in Human Performance. Champaign, IL: Human Kinetics; 2009.

17. Brumitt J, Heiderscheit BC, Manske RC, Niemuth PE, Rauh MJ. Off-season training habits and preseason functional test measures of division iii collegiate athletes: a descriptive report. Int J Sports Phys Ther. 2014;9(4):447-455. PubMed ID: 25133073

18. Rauh MJ, Koepsell TD, Rivara FP, Margherita AJ, Rice SG. Epidemiology of musculoskeletal injuries among high school cross-country 
runners. Am J Epidemiol. 2006;163(2):151-159. PubMed ID: 16306308 doi:10.1093/aje/kwj022

19. Brumitt J, Engilis A, Eubanks A, Mattocks A, Peet J, Bush N. Risk factors associated with noncontact time-loss lower-quadrant injury in male collegiate soccer players. Sci Med Football. 2017;1(2):96-101. doi:10.1080/24733938.2017.1282164

20. Petschnig R, Baron R, Albrecht M. The relationship between isokinetic quadriceps strength test and hop tests for distance and one-legged vertical jump test following anterior cruciate ligament reconstruction. J Orthop Sports Phys Ther. 1998;28(1):23-31. doi:10. 2519/jospt.1998.28.1.23

21. Pincivero DM, Lephart SM, Karunakara RG. Relation between open and closed kinematic chain assessment of knee strength and functional performance. Clin J Sport Med. 1997;7(1):11-16. PubMed ID: 9117519 doi:10.1097/00042752-199701000-00003

22. Blackburn JR, Morrissey MC. The relationship between open and closed kinetic chain strength off the lower limb and jumping performance. J Orthop Sports Phys Ther. 1998;27(6):430-435. PubMed ID: 9617729 doi:10.2519/jospt.1998.27.6.430

23. Fischer F, Blank C, Dunnwald T, et al. Isokinetic extension strength is associated with single-leg vertical jump height. Orthop J Sports Med. 2017;5(11):2325967117736766. PubMed ID: 29147670

24. Yasuda T. Field-based simplified approach of evaluating knee extensor muscle strength and size in university freshmen women [published online ahead of print December 18, 2017]. J Sport Rehabil. PubMed ID: 29252077 doi:10.1123/jsr.2017-0181

25. James LP, Kelly VG, Beckman EM. Injury risk management plan for volleyball athletes. Sports Med. 2014;44(9):1185-1195. PubMed ID: 24849543 doi:10.1007/s40279-014-0203-9

26. Bonita R, Beaglehole R, Kjellstrom T. Basic Epidemiology. 2nd ed. Geneva, Switzerland: World Health Organization; 2006.

27. Jewell DV. Guide to Evidence-Based Physical Therapist Practice. 2nd ed. Sudbury, MA: Jones \& Bartlett Learning; 2011. 